\title{
Thermomechanical modeling of cooling slabs under a hood after continuous casting
}

Patrik Wikström, Christer Nilsson and Fredrik Berntsson

The self-archived postprint version of this journal article is available at Linköping University Institutional Repository (DiVA):

http:/ / urn.kb.se/ resolve?urn=urn:nbn:se:liu:diva- 143362

N.B.: When citing this work, cite the original publication.

Wikström, P., Nilsson, C., Berntsson, F., (2017), Thermomechanical modeling of cooling slabs under a hood after continuous casting, MATERIALS RESEARCH EXPRESS, 4(11), .

https:// doi.org/ 10.1088/2053-1591/ aa9858

Original publication available at:

https:/ / doi.org/ 10.1088/ 2053-1591/ aa9858

Copyright: IOP Publishing (Hybrid Open Access)

http:// www.iop.org/ 


\title{
ARTICLE \\ Thermomechanical modeling of cooling slabs under a hood after continuous casting
}

\author{
Patrik Wikström $^{\mathrm{a}}$ and Christer Nilsson ${ }^{\mathrm{a}}$ and Fredrik Berntsson ${ }^{\mathrm{b}}$

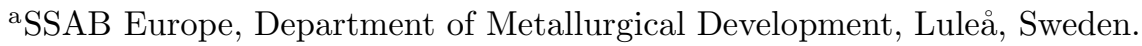 \\ ${ }^{\mathrm{b}}$ Department of Mathematics, Linköping University, Linköping, Sweden.
}

\author{
ARTICLE HISTORY
}

Compiled June 22, 2017

\begin{abstract}
Subsequent cooling of slabs after continuous casting is an important step to control before further processing such as hot-rolling. In this work the stresses that occur in slabs during the cooling process were investigated by using a finite element model. In the specific situation that we model a stack of slabs are left to cool under a hood, insulated by a ceramic material, which makes the cooling slower and the temperature distribution more even during the cooling process. The accuracy of the numerical model was validated by a comparison with temperature measurements, and also by a comparison with hot tensile tests for the specific cooling situation under investigation. The results show that the highest stress levels achieved during cooling did not exceed the mechanical strength of the material at the temperatures investigated.
\end{abstract}

\section{KEYWORDS}

Continuous casting, Slab cooling rate, Tensile tests, Numerical Simulations.

\section{Introduction}

Continuously cast slabs are generally stacked on top of each other while cooling before further processing, e.g. rolling, takes place. Obviously, part of the reason for this is limited space in the slab yard. However, slow cooling is also put on as a requirement for certain types of steels in order to avoid problems during subsequent processing as the cooling rate can influence the micro structure of the steel $[1,2]$. Several problems can occur in a slab during the cooling process before it is rolled into a hot band coil. These problems can affect the ability to roll the slab properly or the quality of the coil. For example, a slab can bow up or down as it cools in the slab yard and surface cracks can form due to chemical sensitivity $[3,4]$, for instance the excess hydrogen in the steel can create cracks. Controlling the cooling process can reduce these problems.

There is a temperature gradient across the thickness of the slabs as they exit from the continuous casting machine. The core has just solidified at the end of the casting process. Throughout the casing the surfaces are kept around $800-1000^{\circ} C$ to keep the material in the ductility zone in order not to decrease the surface quality. After leaving the caster the slab is transported to the slab yard where it is to be placed for 

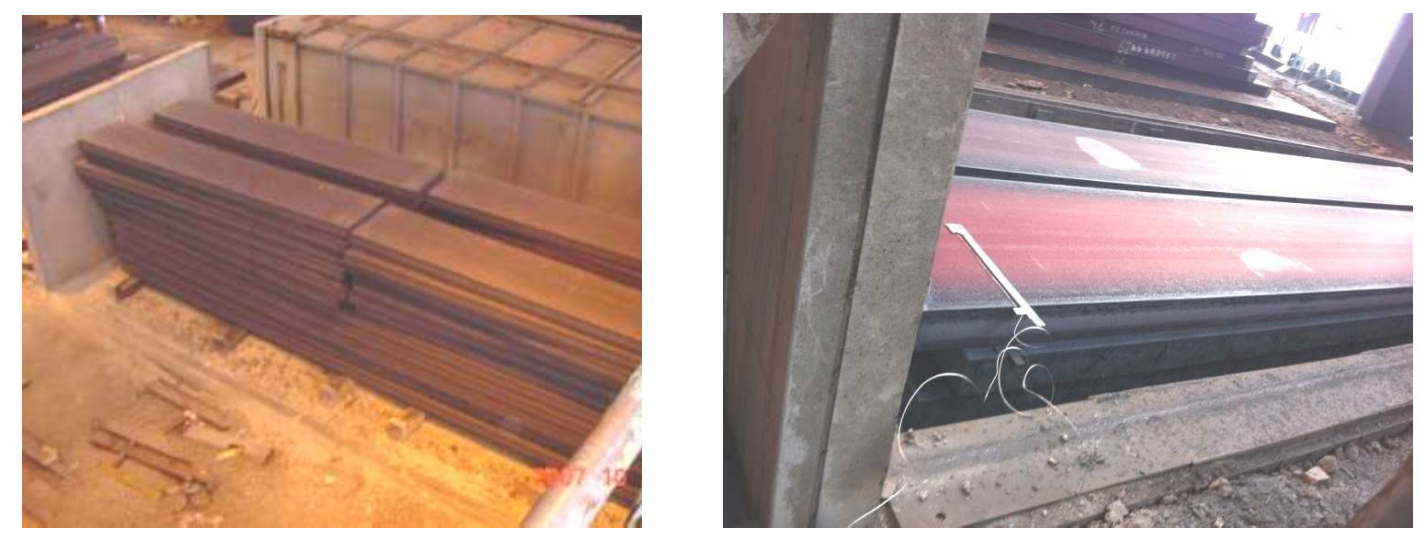

Figure 1. The placement of the steel slabs in two stacks during the cooling experiment (left). At the top of the respective piles extra half-length cool slabs are placed to prevent large deformations in the other slabs during the cooling. We also show the placement of the thermocouples inserted between the slabs of one of the stacks using a specially constructed holder (right).

cooling. Its surface is immediately starting to cool through convective and radiative heat transfer to the surroundings.

During the cooling process the temperature gradient in the slab is slowly decreasing through diffusion. This will create a thermal load in the slab since, as the temperature drops, the steel shrinks. The colder surface shrinks faster than its warmer core. Thus stresses and strains develop during the cooling process. Large and quickly changing temperature gradients may be detrimental to certain steel qualities and must be avoided[5-7].

The aim of this work is to investigate the stresses that develop during the cooling process starting after the continuous casting, and before the slabs are moved into the reheating furnace and also prior to the rolling mill operations. In particular we are interested in the effect the thermal stresses, during the cooling process, have on the tensile strength of the slabs. For this purpose a finite element model is used to calculate both the temperature of the steel slabs during the cooling period and also to calculate stresses inside the material. The finite element model is tuned in such a way that its output coincides with temperature measurements taken at number of locations inside the stack. We also validate our calculations by comparing the calculated stresses, by the finite element model, to actual measured stresses in a tensile test. This gives a possibility to ensure that the cooling rates are appropriate for the steel quality. This is important since problems may arise if the calculated stresses exceed the strength of the material.

\section{Modeling of the cooling process}

The situation that we attempt to model consists of ten slabs that are stacked on top of each other. The dimension of the slabs are $11 \times 1.5 \times 0.2 \mathrm{~m}$. In order to reduce the thermal gradients the stack itself is contained within a hood which is insulated with a ceramic material. This keeps the cooling sufficiently slow and potentially results in a relatively small thermal gradient during the cooling process. In our experiment two piles of ten slabs each were cooling beside each other. In Figure 1 we show the placement of the stacks, in the slab yard, during the cooling process. The hood is seen 


\begin{tabular}{|c|c|c|c|c|c|c|}
\hline Steel A & $\mathrm{C}$ & $\mathrm{Si}$ & $\mathrm{Mn}$ & $\mathrm{Cr}$ & $\mathrm{Nb}$ & $\mathrm{Al}$ \\
\hline Weight (\%) & 0.15 & 0.20 & 1.80 & 0.45 & 0.015 & 0.035 \\
\hline
\end{tabular}

Table 1. The chemical composition of the steel grade used in our experiment.

in the background.

In the work we used the commercial software LS-Dyna ${ }^{1}$ for the numerical modeling. The details of the model is as follows: The transient temperature in the interior of the slabs is governed by the heat equation, i.e. the temperature $T(\vec{r}, t), \vec{r}=(x, y, z)$, satisfies

$$
\nabla \cdot(k \nabla T)+q=c_{p} \rho \frac{\partial T}{\partial t},
$$

where $k$ is the thermal conductivity, $c_{p}$ is the specific heat, $\rho$ is the density, and $q$ is a source term that appears due to phase transitions.

The proper values of the material parameters that appear in (1) depends on the specific composition of the steel used in the experiment. In our work we use a material we refer to as Steel Grade A. The composition is shown in Table 1. For this specific grade of steel we have used a material model that implements a thermo-elastical constitutive relation, with isotropic hardening for both global and local plastic creep. The model includes transformation induced plasticity due to Greenwood and Johnson [8]. This means that if a lower deviatory stress than the global creep stress exists in the material when a coincident phase transformation (solid-solid) takes place, then the soft austenite will plastify locally. Both the local and global creep law is associative; i.e. plastic creep is taking place normal to the surface. The actual implementation uses a linear mixed law to determine both the global and local yield stresses.

The mechanical constitutive model also includes the transformations that take place depending on the thermal and mechanical history. The austenite decomposition model is based on Kirkaldys ordinary differential equations [9], with modifications according to $\mathrm{Li}[10]$. The final thermal model is isotropic and the thermal conductivity and specific heat are both determined by the temperature and the micro structures of the material at the specific location and time instance. Furthermore, also the latent heat that is released upon the austenite decomposition into daughter phases is included as a heat source.

After continuous casting the temperature is approximately around $1450^{\circ} \mathrm{C}$ in the core of the slab and about $1000^{\circ} \mathrm{C}$ on the surface. In the simulations the initial assumption is that the temperature in the slabs are homogeneous and starting at $900^{\circ} \mathrm{C}$. This is of course a departure from reality. However the material is very ductile at high temperatures with the ability to self-repair through diffusion. Also, relaxation through creep lowers tensions. These mechanisms are not included in the material models. However, developed strains in the austenite is not heritable to the new daughter phase, thus there will be a stress relaxation. The simulations in this work start above the critical temperatures where austenite can decompose into ferrite and perlite.

The lateral surfaces and upper surface of the top slab exchange heat with the surroundings, i.e. the hood, through a combination of radiative and convective heat trans-

\footnotetext{
${ }^{1}$ See http://www.lstc.com/products/1s-dyna for further information.
} 
fer [11]. This is modelled by

$$
k \frac{\partial T}{\partial \vec{n}}=h_{\text {conv }}\left(T-T_{\infty}\right)+\varepsilon \sigma\left(T^{4}-T_{w a l l}^{4}\right),
$$

where $h_{\text {conv }}$ is the convective heat transfer coefficient, $T_{\infty}$ is the air temperature inside the hood, $\varepsilon$ is the emissivity, $\sigma$ is the Stefan-Boltzmann constant, and $T_{\text {wall }}$ is the temperature of the hood itself. The convective part of the heat transfer was modelled by assuming natural convection on a vertical wall. A similar boundary condition is added for the interaction between the hood and its surroundings. We remark that the numerical model is non-linear as most of the physical parameters in the model are temperature dependent.

In the finite element model a structural mechanical problem is coupled to the thermal problem. The stresses that appear are thus regarded as coming from both thermal gradients as well as from elastic-plastic behavior of the material. The constitutive equation describing this link is written as,

$$
\frac{\partial \sigma}{\partial t}=\frac{\partial \sigma_{T}}{\partial t}+\frac{\partial \sigma_{e}}{\partial t}
$$

where $\sigma$ is the stress tensor and $\sigma_{T}$ and $\sigma_{e}$ are the respective contributions from the thermal- and the mechanical problems.

Thermal and mechanical conditions are formulated for the contact between surfaces in order to reflect reality as closely as possible. The slabs are able to move relative each other if the friction between them can be overcome. The friction coefficient is set to 0.2 in order to reflect oxidized steel surfaces. The slabs can also bend in relation to each other so that a certain degree of separation between the ends of slabs can be achieved. Heat transfer between slabs is considered to take place through conduction as long as the distance between them is less than $0.1 \mathrm{~mm}$. Otherwise, we have heat transfer by radiation and conduction through the air between the slabs.

The thermal emissivity of an oxidized steel slab, i.e. with a thin layer of scales formed on the surface, is set to 0.8. Slabs in contact with each other transfer thermal energy between them via surface heat transfer set to $1200 \mathrm{~W} /\left(\mathrm{m}^{2} \cdot{ }^{\circ} \mathrm{C}\right)$ and the equivalent for slabs resting against the floor is set to $800 \mathrm{~W} /\left(\mathrm{m}^{2} \cdot{ }^{\circ} \mathrm{C}\right)$. Gravity is acting on each slab and is set $g=9.82 \mathrm{~m} / \mathrm{s}^{2}$.

In order to minimize the calculation times, the symmetry of the problem was taken into consideration. Only half of the length and the width of the slabs were modelled. One surface is in contact with the floor (or other slabs) and two or three (the upper slab) surfaces transfer heat by convection and radiation to the surroundings and the remaining two surfaces are symmetry planes in the model. Every quarter of a slab is represented by 2000 hexagonal elements. Since only one quarter of the slab was modelled, there are two sides of each slab that are used as symmetry planes.

\section{Temperature measurements and model validation}

In order to verify the validity of the finite element model we conducted an experiment where two stacks, each consisting of ten slabs, where cooling next to each other as seen in Figure 1. The temperature was measured at four different positions in one of the stacks during 48 hours. The thermocouples where placed, using a specially manufactured thermocouple holder, and placed near the near the short end of the slabs. The 

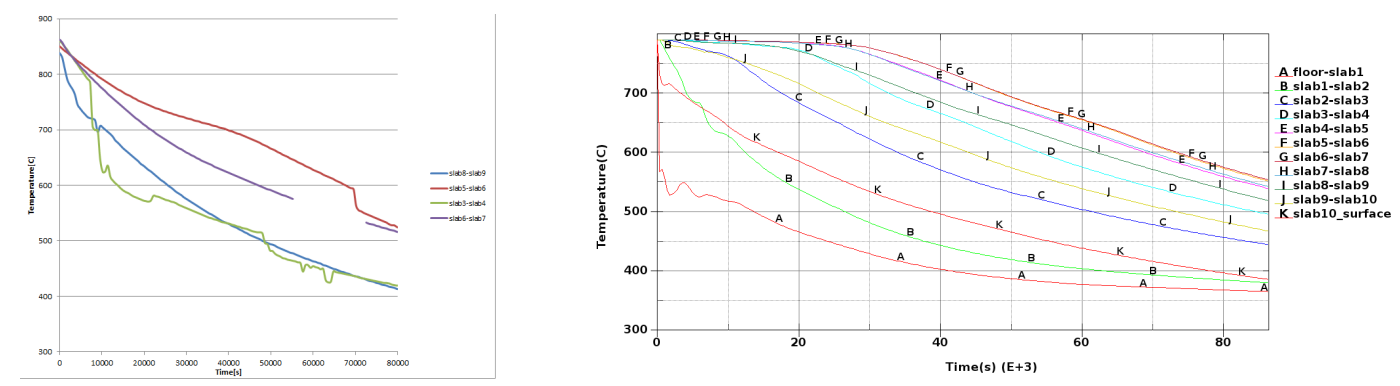

Figure 2. The measured temperatures obtained by thermocouples placed inside one of the slab piles. The thermocouples are placed between slabs 3-4, slabs 5-6, slabs 6-7, and slabs 8-9, counted from the bottom of the pile. We also display the computed temperature histories in between all the slabs at the end obtained by the finite element model (right).

goal is to verify that the finite element model can predict the measured temperatures with sufficient accuracy.

In Figure 2 we show the results. The temperatures at the beginning were around $820-860^{\circ} \mathrm{C}$. The cooling is slower in the middle of the stack, i.e. between slab five and six, and after approximately 13 hours the temperature is just a little bit above $700{ }^{\circ} \mathrm{C}$, which coincides with the temperature where phase transitions takes place[12]. A small increase in temperature accompanies the phase transformation due to the release of latent heat. The other cooling curves do not exhibit this feature. The reason may that the heat release is too small to compensate for the higher cooling rate closer to the top and bottom of the stack. Halfway through the experiment, the temperature is still about $400-500^{\circ} \mathrm{C}$. During the next 24 hours the cooling rate is slower. At the end of the experiment, after 50 hours, the measured temperatures are still around $240-380^{\circ} \mathrm{C}$.

In order to validate the model we calculate the corresponding temperatures at the locations where the thermocouples were placed. We also calculate the temperature at the middle of the slabs. The results are shown in Figure 2. The calculated temperature histories show very similar, but not exactly, matching curves as those from the measurements.

An essential difference is that the modeling was done with ten hot slabs whereas during the measurements a cold slab was positioned on top of the ninth. This is common practice, in order to assure that the slabs are as straight as possible after cooling, but was not accounted for in the simulations as the material model cannot handle heating as its developed curves for phase transformations consider cooling only. Still the modeled temperatures fall essentially in the same range as the measured ones for the entire duration of the experiment.

Note also that the slab in direct contact with the floor shows a rapid decrease in temperature due to the initial temperature shock. Here the calculated temperatures deviate somewhat from the measured ones. One reason is that it was not possible to place the thermocouple at the exact same place between all slabs. Also, the slabs may move slightly, and can even separate, meaning that the measurement point may not in reality be in contact with the surface of both the slabs. Furthermore, there is a thin oxide layer on the surface of the slabs, due to both continuous casting as well as the exposure to air before cooling. Despite these difficulties, since the primary aim is to calculate representative stress levels during the cooling, the accuracy of the the simulated temperatures, obtained using the finite element model, are considered to be 
(a) Yield stress $\left(10^{6} \cdot \mathrm{Pa}\right)$

\begin{tabular}{|c|r|r|r|r|}
\hline Temp $\left({ }^{\circ} \mathrm{C}\right)$ & Max & Min & Mean & Std Dev \\
\hline \hline 200 & 324.0 & 299.6 & 309.9 & 8.6 \\
\hline 400 & 334.2 & 261.4 & 300.9 & 20.4 \\
\hline 600 & 212.6 & 205.1 & 209.6 & 2.4 \\
\hline 800 & 61.0 & 51.3 & 55.1 & 2.7 \\
\hline
\end{tabular}

(b) Fracture stress $\left(10^{6} \cdot \mathrm{Pa}\right)$

\begin{tabular}{|c|r|r|r|r|}
\hline Temp $\left({ }^{\circ} \mathrm{C}\right)$ & Max & Min & Mean & Std Dev \\
\hline \hline 200 & 484.8 & 457.0 & 573.5 & 10.2 \\
\hline 400 & 459.1 & 441.2 & 451.1 & 6.2 \\
\hline 600 & 241.5 & 235.0 & 238.9 & 2.1 \\
\hline 800 & 77.4 & 69.2 & 73.1 & 2.4 \\
\hline
\end{tabular}

(c) Elongation (\%)

\begin{tabular}{|c|c|c|r|r|}
\hline Temp $\left({ }^{\circ} \mathrm{C}\right)$ & Max & Min & Mean & Std Dev \\
\hline \hline 200 & 18.8 & 22.1 & 15.7 & 2.2 \\
\hline 400 & 23.8 & 30.1 & 11.6 & 5.2 \\
\hline 600 & 19.5 & 23.9 & 16.9 & 2.4 \\
\hline 800 & 37.1 & 49.5 & 22.4 & 7.5 \\
\hline
\end{tabular}

Table 2. The average values for the yield stress, fracture stress and elongation calculated from the tensile tests.

satisfactory. Our conclusion is that the finite element model is sufficiently accurate and can be used to estimate thermal stresses that appear during the cooling.

\section{Tensile tests}

After the cooling was complete, and the temperature histories had been recorded by the thermocouples, we performed an experimental investigation of the mechanical properties of the steel slabs at several locations. A total of 32 samples were cut out from the cooled slabs. The test was divided into groups to investigate whether the cast structure material would behave differently in different directions. Half of the samples were taken out along the length of the slab and the other half across the width. Further half of the samples were taken from the surface of the slabs and half were taken from the core. This means that we divide our samples in four different groups: Group 1 consists of samples taken along the length direction close to the surface, Group 2 are samples taken in the length direction but from the core of the slab. Similarly Group 3 represents samples from the surface of the slab taken along the width of the slab and finally Group 4 consists of samples taken from the core in the width direction. Each group thus consists of eight different samples.

From each sample a standard tensile bar was manufactured and tensile tests [13] were performed at four relevant temperatures, i.e. $200,400,600$ and $800^{\circ} C$. The results are shown in Figure 3 where the tension for each test bar is plotted against the strain. We see that the steel is ductile at high temperatures and cannot take too much load. The results indicate that there is not much difference between the different groups of samples. Thus the material seems to behave essentially the same regardless of the location and orientation of the test sample. It was decided to treat all the tests as coming from one and the same group for the purpose of calculating the yield stress, the fracture stress and elongation. The results are shown in Table 2. 

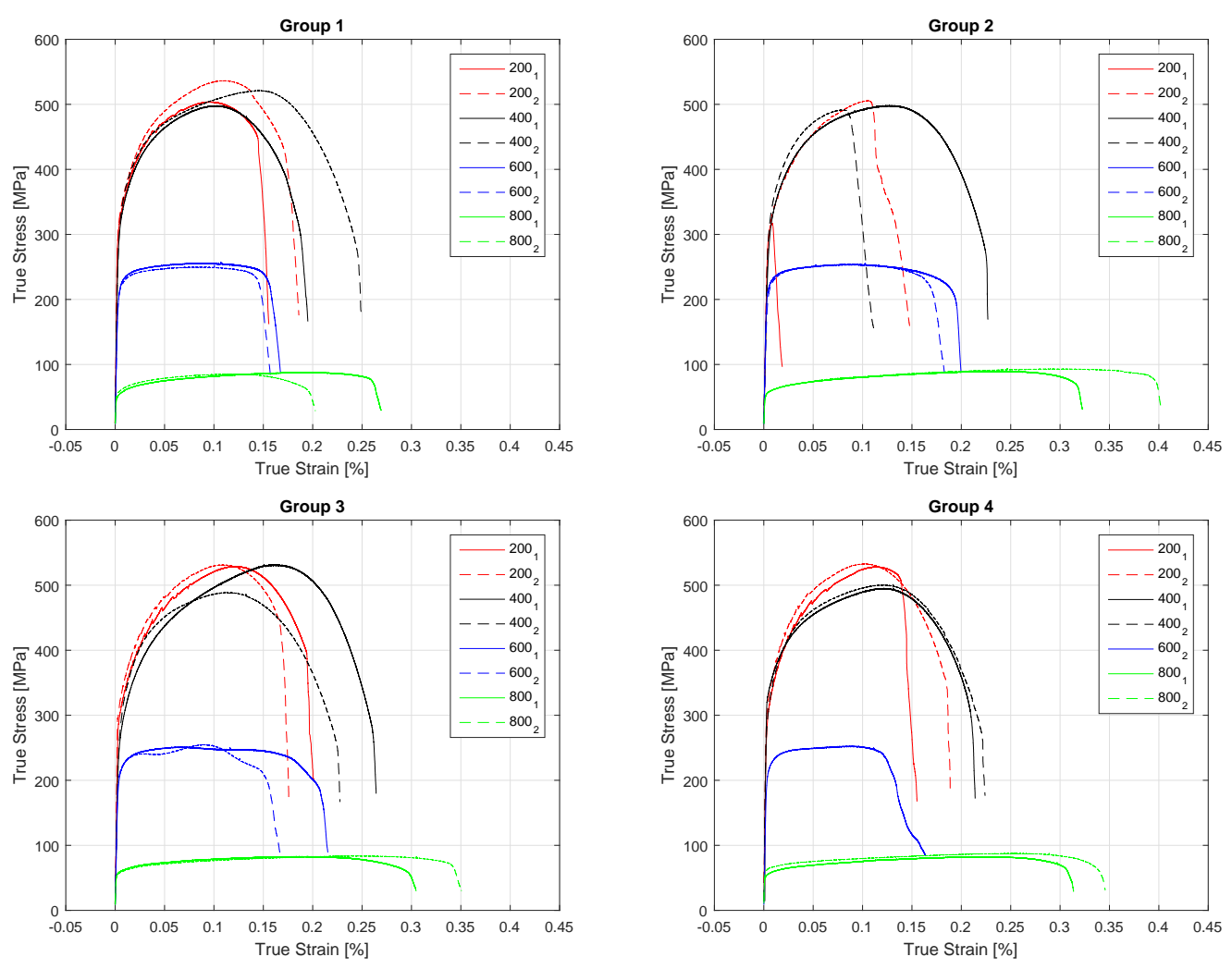

Figure 3. The tensile tests for the four different groups of samples.

\section{Calculation of stresses}

In this section we set out to examine some interesting features such as if the position of the slabs matter. To do this we concentrate our calculations on two different slabs, the one at the bottom and also the one in the middle (number five from the bottom). The results from the strength tests are compared to the calculated stresses.

The finite element model of the slabs includes both thermal and mechanical effects. In order to present the results we selected a number of positions on each slab where the thermal history, stresses, deformation, etc, are computed. The positions are displayed in Figure 4 . The nine positions are labeled $A-I$. In addition, at each location, we calculate the stresses at both the upper surface and at the core, of the slab. This means that we calculate the stresses at a total of 18 locations for each slab.

The principal stresses are shown as it is of interest to analyze if a certain position is under positive or negative stress and how it changes with time. Figure 5 shows the principal stresses at nine points on the upper surface of the bottom slab. Stresses of high magnitude develop quite early and arise due to the phase transformation from austenite to ferrite. The maximum magnitude of the tensile stress is around $100 \mathrm{MPa}$. The slab at the bottom of the pile is under the weight of about 225 metric tons which is equivalent to a pressure of about $0.1 \mathrm{MPa}$. This magnitude of the stress is almost negligible compared to the stresses that arise during the cooling. In a few points situated along the edge of the slab, the stresses arises to a little less than $40 M P a$ and stay constant throughout the cooling process. As the stress curves do not go down to zero this means that residual stresses are built into the slabs during the cooling. 


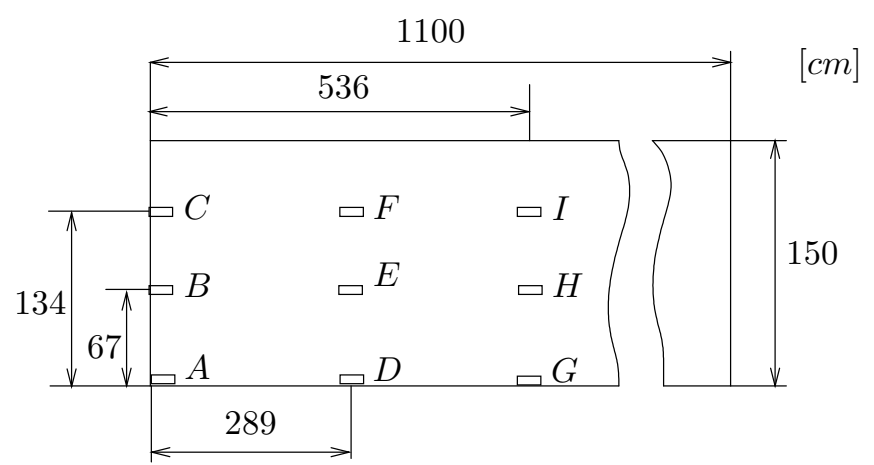

Figure 4. The locations on each slab were the results from the stress calculations are recorded. At each slab location we record the computed stresses at the upper surface and also at the core, which is $11 \mathrm{~cm}$ from the surface.

The bottom slab experiences a faster cooling as it is in contact with the floor and consequently the phase transformations occur earlier at the bottom slab than for slabs in the middle of the stack. The peak of the principal stress that develops during the cooling is plotted against temperature in Figure 6. The tensile stresses reaches a maximum of about $95 \mathrm{MPa}$ and the corresponding temperature is about $745^{\circ} \mathrm{C}$. From the tensile tests, we know that at $800^{\circ} \mathrm{C}$ the fracture stress level is around $77 \mathrm{MPa}$ and at $600^{\circ} \mathrm{C}$ it has increased to $212 \mathrm{MPa}$. Unfortunately, there are no experimental values in between $600^{\circ} \mathrm{C}$ and $800^{\circ} \mathrm{C}$ and there is a lack of knowledge how the stress changes since the dependence on temperature is non-linear. If one still ties a linear interpolation, the fracture stress is going to be above the stress obtained in the calculation. The results presented in Figure 5 also shows that the plastic deformation takes place early and that no further strain develops after this. The magnitude of the largest strain shows that the elongation of around $0.5 \%$ which is considerably low. However, the yield stress was reached and there will be a plastic strain in the surface of the material however it is rather small. Also at the core points, at a depth of about $11 \mathrm{~cm}$ beneath the surface, see Figure $6 \mathrm{~d}$, behaves in essentially the same way. The magnitude of the stresses are almost identical the first 10000 seconds and somewhat higher after this, but as seen in Figure 5, the most detrimental stresses are those that appear in the beginning when considering the temperature.

A slab in the middle of the stack, e.g. number five, behaves in a different way. From the temperature curves in Figure 2 it is evident that the temperature drop is considerably smaller than for the bottom slab. As for the stress curves on the top surface of the middle slab, see Figure 7, initially a mildly oscillating behavior is seen until about 7 hours when the curves are separating. Phase transformation takes place and the magnitude increases. The residual stresses are also high, about $130 \mathrm{MPa}$ after 24 hours of cooling on top surface of the middle slab. There is no essential difference in the behavior of the stress in the interior of the slab, as can be seen in Figure 7. We also show the stress at location $D$ but this time plotted against temperature in Figure 6 . The hilly part around $730-770^{\circ} \mathrm{C}$ represent the phase transformation to ferrite. When the temperature is under $700^{\circ} \mathrm{C}$, the stresses increase until the temperature is around $580^{\circ} \mathrm{C}$ where the maximum level is reached. Hereafter, the stress level falls slightly until the end of the cooling when the temperature in the middle slabs is still quite high. The experimental tensile tests show that the limit for fracture is not surpassed in the middle slab.

Many of the stress curves change multiple times from compressive to tensile stresses 

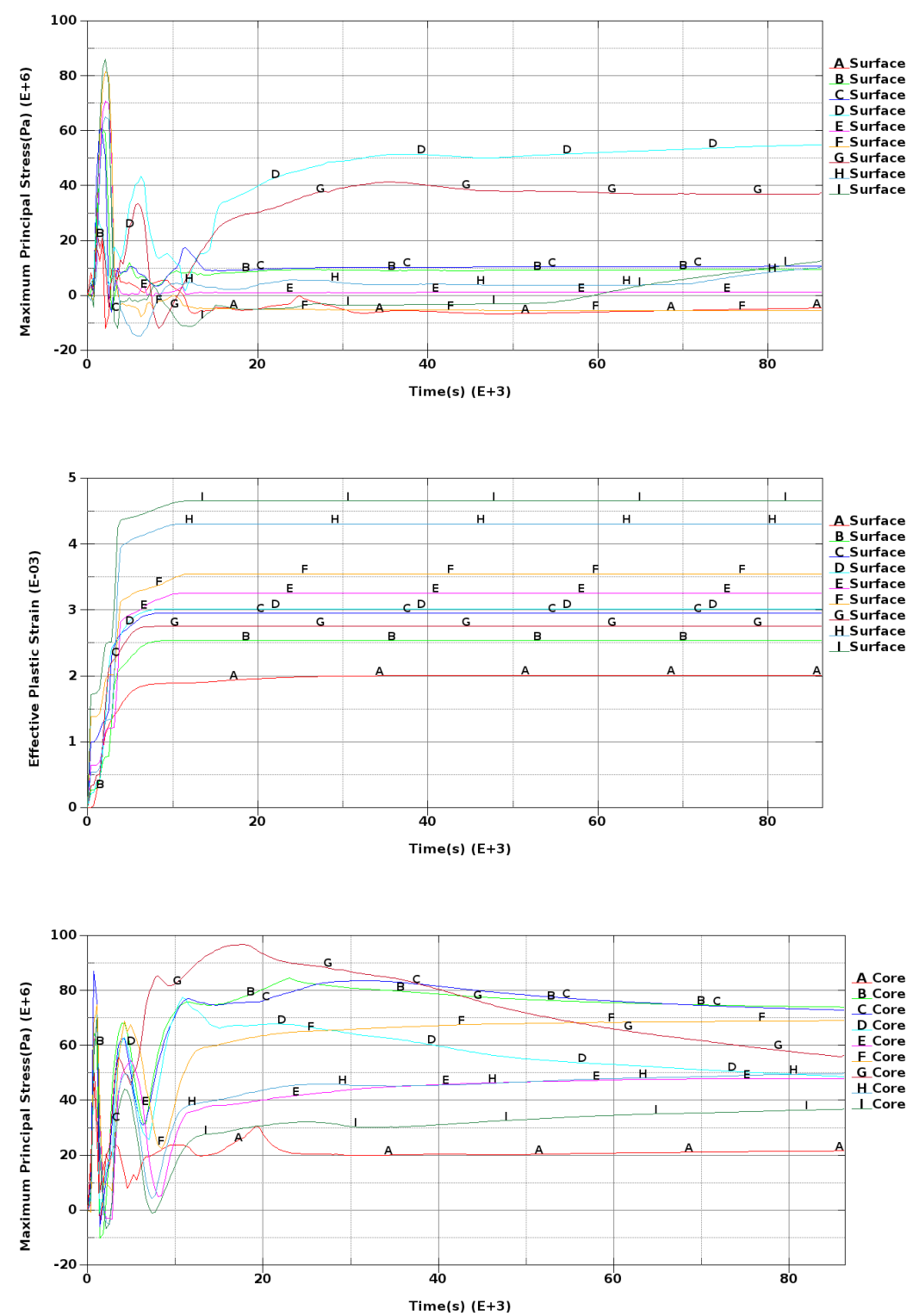

Figure 5. The calculated results for the bottom slab, i.e. Slab 1, at the nine selected locations. We show the calculated stresses at the upper surface (top). The effective plastic strains at the surface (middle) and the stresses at the core of the slab (bottom) are also displayed

before stabilizing after about 21 hours on a level that is maintained throughout the rest of the cooling period. The material tries to shrink during the cooling which means that surrounding structure tries to withstand this. Different parts of the slab are affected by the volume changes in other parts. A complicated pattern of compressive and tensile stresses is ongoing. Plastic deformation takes place in what seems to be in different stages, see Figure 7. Some points, locations $F$ and $I$, exhibit a slower cooling at the middle of the slab and take the longest to find a plateau. No further plastic deformation is observed after this, probably due to deformation hardening. The magnitude of the largest strain shows that the elongation of around $0.4 \%$ which is considerably low. 

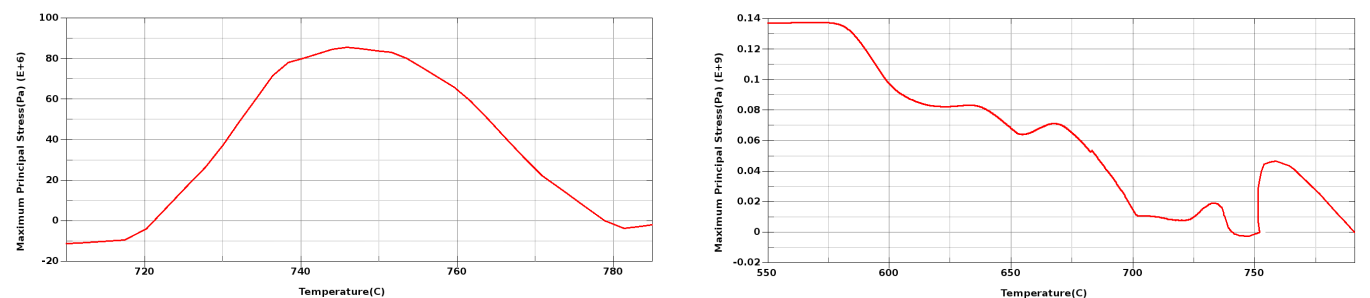

Figure 6. We display the maximum stress at the upper surface of the slab as a function of temperature. The results for Slab 1 (left) and for Slab 5 (right) are both presented.
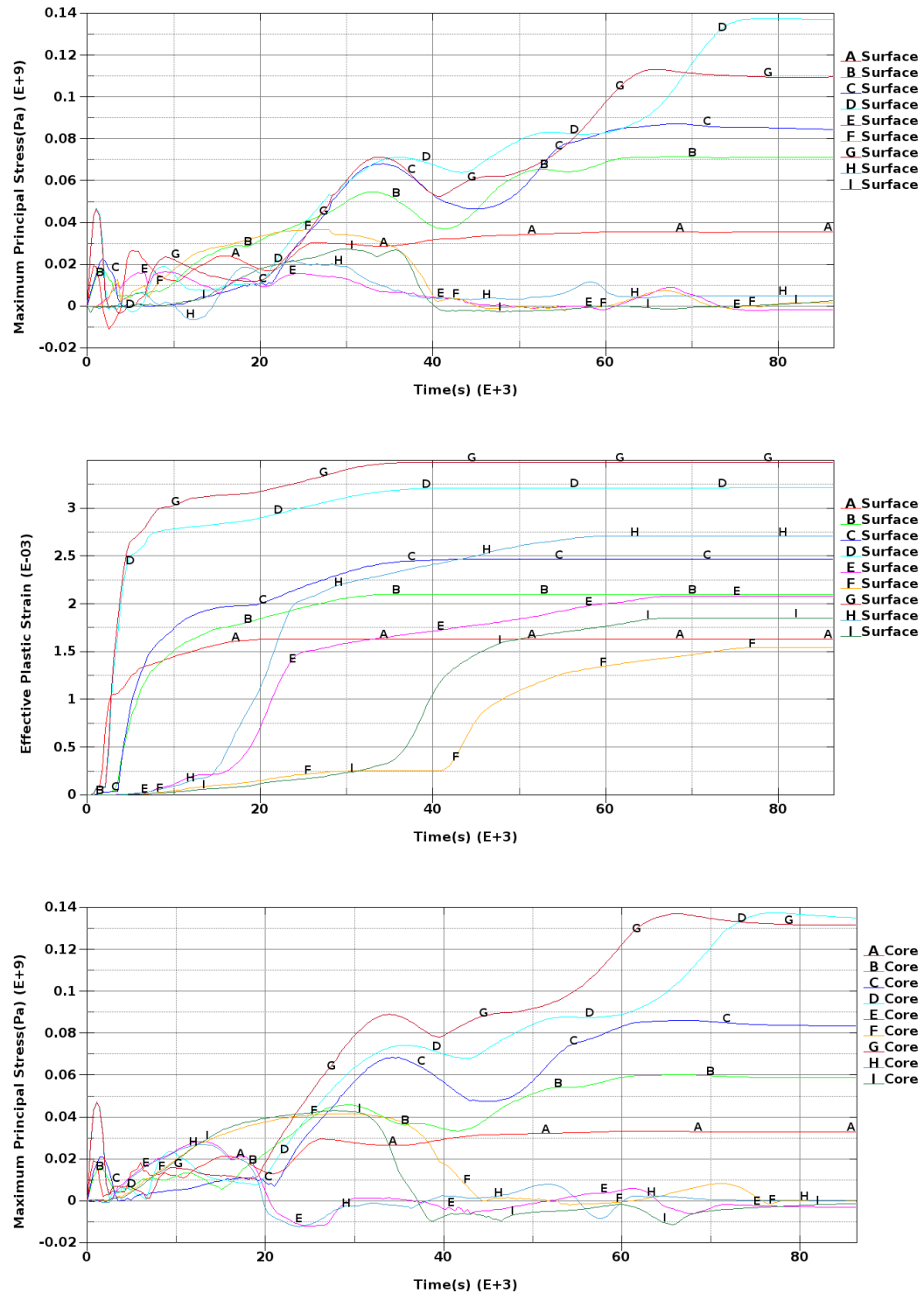

Figure 7. The calculated results for slab 5, i.e. the middle slab, at the nine selected locations. We show the calculated stresses at the upper surface (top). The effective plastic strains at the surface (middle) and the stresses at the core of the slab (bottom) are also displayed 


\section{Concluding remarks}

The stress levels developing during cooling after continuous casting were investigated. The stresses were large at phase transformation temperatures and the position in the stack matters as the temperature history is different at slabs in the middle or bottom positions. Tensile tests showed that the stress levels were close but never exceeding the critical ones at the investigated temperatures.

There is however at least a partial lack of information in the range $600-800^{\circ} \mathrm{C}$ as there was a sudden shift in the mechanical strength at the endpoints of this interval. Problems during subsequent operations should not occur due to this as long as the material is defect free. Problems can arise if there are interior cracks in the slabs prior to the cooling emanating from continuous casting in which case the material can suffer from high stress concentrated at these areas. This could propagate an initiated crack.

\section{References}

[1] Ma FJ, Wen GH, Tang P, et al. In situ observation and investigation of effect of cooling rate on slab surface microstructure evolution in microalloyed steel. Ironmaking \& Steelmaking. 2010;37(3):211-218.

[2] Fan Y, Wang Q, Liu H, et al. Effect of controlled cooling on microstructure and tensile properties of low c nb-ti-containing hsla steel for construction. Metals. 2017;7(1).

[3] Mendoza R, Huante J, Alanis M, et al. Slab cracking after continuous casting of api 5l x-70 grade steel for pipeline sour gas application. Ironmaking \& Steelmaking. 1999; 26(3):205-209.

[4] Brimacombe J, Sorimachi K. Crack formation in the continuous casting of steel. Metallurgical Transactions B. 1977;8(2):489-505.

[5] Sengupta J, Thomas BG, Wells MA. The use of water cooling during the continuous casting of steel and aluminum alloys. Metallurgical and Materials Transactions A. 2005; 36(1):187-204.

[6] Allazadeh MR, Garcia CI. Fem technique to study residual stresses developed in continuously cast steel during solid solid phase transformation. Ironmaking \& Steelmaking. 2011; $38(8): 566-576$.

[7] Allazadeh MR. Cooling rate optimization of as-cast consciously cast steel. Iranian Journal of Materials Science \& Engineering. 2012;9.

[8] Greenwood GW, Johnson RH. The deformation of metals under small stresses during phase transformations. Proceedings of the Royal Society of London A: Mathematical, Physical and Engineering Sciences. 1965;283(1394):403-422.

[9] Kirkaldy S, D Venugopalan D. Prediction of microstructure and hardenability in low alloy steels. In: Marder AR, Holstein J, editors. International Conference on Phase Transformations in Ferrous Alloys; Metallurgical Society of AIME; Philadelphia; 1983. p. 125-128.

[10] Li MV, Niebuhr LL David Vand Meekisho, Atteridge DG. A computational model for the prediction of steel hardenability. Metallurgical and Materials Transactions B. 1998; 29(3):661-672.

[11] Holman JP. Heat transfer, 7th ed. McGraw Hill; 1992.

[12] Long M, Dong Z, Chen D, et al. Influence of cooling rate on austenite transformation and contraction of continuously cast steels. Ironmaking \& Steelmaking. 2015;42(4):282-289.

[13] Davis JR. Tensile testing. 2nd ed. ASM International; 2004. 